\title{
Parathyroid Gland FNA and PTH Washout; Diagnostic Value in Patients with Primary Hyperparathyroidism
}

\author{
Rania Al-Asa'd ${ }^{* 1}$, Ali Alzu'bi ${ }^{1}$, Susan Eteiwi ${ }^{1}$, Abdallah Al Eyadeh ${ }^{1}$, Khaldon Al-Sarihin ${ }^{1}$, Reem Al-Qaddah ${ }^{1}$, \\ Adnan Zayadeen ${ }^{2}$, Ahmad Al-Omari ${ }^{1}$, Fares Haddad ${ }^{1}$, Dina Nasri ${ }^{1}$, Gharam Alawabdeh ${ }^{1}$, Ferdos Faraieh ${ }^{1}$ and \\ Reema Nsairat ${ }^{1}$ \\ ${ }^{1}$ Endocrine Division, King Hussein Medical Center, Royal Medical Services
}

${ }^{2}$ Radiology Department, King Hussein Medical Center, Royal Medical Services, Amman-Jordan

\begin{abstract}
Received: January 11,2019; Accepted: January 24 ,2019; Published: February 02, 2019
*Corresponding author : Dr. Rania Al-asa'd, Endocrine Division, King Hussein Medical Center, Royal Medical Services, Jordan,Tel: +962 772447568;E-mail: Raniamd@yahoo.com
\end{abstract}

\section{Abstract}

Primary hyperparathyroidism is the most common cause of hypercalcemia in outpatients and it is usually attributed to parathyroid adenoma, which is managed by surgical resection of the adenoma. Successful management requires accurate localization of the adenoma prior to surgery.

Objective: To describe our institution's experience in assessing the diagnostic value of parathyroid Fine Needle Aspirate (FNA) and PTH washout in localizing and confirming parathyroid adenoma.

Methods: Twenty three patients ( $91.3 \%$ females) diagnosed to have primary hyperparathyroidism(PHPT) were enrolled in our study: parathyroid scanning (sestamibi), Ultrasound (US)and USguided FNA of the suspected parathyroid adenoma done to all patients by the same radiologist. The aspirate form FNA was washed out with one centimeter cubic normal saline and PTH was measured in the washout.

Results: Mean $( \pm$ SD) age was $51.3 \pm 13.5$ year. Mean serum PTH ( 289.3 \pm 384.7$) \mathrm{pg} / \mathrm{ml}$ and mean serum Calcium was $(10.9 \pm 1.2) \mathrm{mg} /$ dl. Mean $( \pm$ SD) PTH values in the washout is $1172.3 \pm 1877.6 \mathrm{pg} / \mathrm{ml}$. Three patients had negative sestamibi scan but had positive results in PTH washout. The sensitivity and specificity of PTH washout are $82 \%$ and $100 \%$ respectively, with $100 \%$ positive predictive value and 67 $\%$ negative predictive value. For Sestamibi scan are $76.5 \%$ and $83.3 \%$ respectively with $92.9 \%$ positive predictive value and $55.6 \%$ negative predictive value and for ultrasound are $76 \%$ and $67 \%$ respectively with $87 \%$ positive predictive value and $50 \%$ negative predictive value.

Conclusion: This study highlights the superiority of Parathyroid FNA with PTH washout over US or sestamibi scanning in confirming a parathyroid adenoma.

\section{Introduction}

Primary hyperparathyroidism is the most common cause of hypercalcemia in outpatients. $90 \%$ of these cases are caused by single parathyroid adenoma and $10 \%$ are caused by hyperplasia and rarely parathyroid gland carcinoma. The curative treatment for primary hyperparathyroidism is surgery and a successful surgery requires accurate localization preoperatively. Preoperative localization of adenoma leads to less invasive surgery with less duration and complications.
Neck Ultrasound (US) and technetium-99m- SESETAMIBI scanning are widely used to localize the adenoma in addition to CT scan, the sensitivity of neck US and SESTAMIBI ranges between $70-90 \%$, there is however false negative percentage reaching about $22 \%$ in some reports. $[1,13,14]$

US-guided parathyroid FNA is becoming widely used to help in localizing the parathyroid adenoma in addition to US and parathyroid scanning because of the accessibility of the neck, cost effectiveness and convenience of the procedure.

It was first described by Doppman et-al in 1983, who reported 7 patients who underwent CT-guided parathyroid gland FNA with measurement of PTH and thyroglobulin. All patients had high PTH washout in at least one specimen, since then several reports described US guided FNA of the suspected parathyroid lesion with PTH washout. [2-6]. The sensitivity of this approach in these reports ranged from 82 to $100 \%$ and specificity from 91 $100 \%$. [1,2,4-6,9].

the PTH washout cutoff level above $100 \mathrm{pg} / \mathrm{ml}$ was considered positive in some studies [9-11]. While other reports a positive result was considered if PTH level in the washout was higher than a concomitant serum PTH. [5-8].

A retrospective review of Mayo Clinic parathyroid hormone analysis in fine-needle aspiration biopsy washings performed between June 2008 and May 2011 identified 42 specimens with confirmed parathyroid tissue ( 19 specimens) and no parathyroid tissue (23 specimens). The essay showed $100 \%$ specificity and $74 \%$ sensitivity for the detection of parathyroid tissue using a cutoff value greater than or equal to $100 \mathrm{pg} / \mathrm{mL}$ as positive. $[10,11]$

Parathyroid hormone measurement in the washed sample after FNA showed superiority in localizing parathyroid adenoma to US and sestamibi scan alone. [2,4-6,8,9,11].

In all of these reports the cytology was less informative in differentiating a parathyroid lesion with $25-55 \%$ sensitivity. $[1,2,3,7,10,11]$. 


\section{Aim of Study}

To assess the diagnostic value of parathyroid gland fine needle aspiration with measurement of PTH in the aspirated material in confirming the parathyroid adenoma and if this technique can be used for preoperative localization of the adenoma in cases requiring surgical treatment of hyperparathyroidism where neck ultrasound and SESTAMIBI scan show no conclusive results.

\section{Methods}

We prospectively studied 23 patients in Endocrine division, King Hussein Medical Center, Amman, Jordan. In the period between August 2016 and November 2017. Patients were diagnosed with primary hyperparathyroidism, based on high or high normal calcium level with high or inappropriately normal serum parathyroid hormone level. Blood samples withdrawn to test for calcium, phosphorus, albumin, alkaline phosphatase level (ALP) and parathyroid hormone in standardized methods . Neck US was performed by the same experienced radiologist to all patients focusing on the description of size, site and vascularity of the suspected nodule with documentation of the presence of multinodular goiter or other associated thyroid nodules; the ultrasound machine used was GE logic S8 with a probe matrix ML6-15. All patients also underwent diagnostic sestamibi scanning.

US guided FNA was then performed using a ten- milliliter syringes mounted in aspirating needle holders with 25 gauge needles. Biopsies were smeared on glass slides and then the syringes were washed with $1 \mathrm{cc}$ of normal saline in a chemistry tube, kept in ice, sent to lab within 30 minutes and the PTH measured in the washout. Simultaneously serum PTH was measured to be compared with PTH in the washout. All smears were fixed in $95 \%$ ethanol and stained with haematoxylin and eosin.

PTH in serum and washout was measured with the immunoassay analyzer Cobas e4111, Immulitte xpi with a detection range $3-5000 \mathrm{pg} / \mathrm{ml}$.

Regarding cytology; specimens were reported as one of the following 4: 1. Parathyroid lesion (adenoma, tumor, neoplasm or tissue), 2. Thyroid lesion, 3. Parathyroid versus thyroid lesion and 4. Inadequate.

Positive result considered when PTH level in the washout is higher than concomitant PTH level in serum. Patients were divided into three groups according to result of PTH washout and surgical outcome:

1. Group 1; those with positive results in PTH washout and positive surgical outcome; parathyroid adenoma identified and excised during surgery and histopathology confirmed it as a parathyroid adenoma.

2. Group 2; those with negative PTH washout and who didn't do surgery (for the reasons mentioned later.)

3. Group 3; those with negative PTH washout and positive surgical outcome.

There were no patients with positive PTH washout and negative surgical outcome.

\section{Statistics}

Statistical analysis was done using descriptive statistics. Age, calcium, phosphorus, ALP, serum PTH and PTH-washout level were expressed as mean \pm SD and were compared among groups using t student test. Sensitivity, specificity, positive and negative predictive values and fisher exact test were calculated using SPSS 17.

\section{Results}

A total number of 23 patients with confirmed biochemical diagnosis of primary hyperparathyroidism were included in the study; their demographic data and biochemical profile and PTH for all and each group are shown in table 1. Fourteen patients (group 1) had positive results with PTH washout level ranged from 72.6 to $5000 \mathrm{pg} / \mathrm{ml}$; mean \pm SD $2372.8 \pm 2021.6 \mathrm{pg} / \mathrm{ml}$. All of them underwent surgical resection of the adenoma in minimally invasive technique without any reported complications and no scar tissue due to previous FNA found in the resected adenoma. Nine cases (group 2 and 3) had negative results in PTH-washout, with a mean PTH-washout level $( \pm$ SD) $15.2 \pm 7.9 \mathrm{pg} / \mathrm{dl}$ in both groups. (Table 1 )

Table 1: shows the demographic data , mean \pm standard deviation of Calcium, Phosphorus, alkaline phosphatase, serum PTH and PTH washout among the three groups and all patients.

\begin{tabular}{|c|c|c|c|c|}
\hline $\begin{array}{l}\text { Parameter } \\
\text { (mean } \pm \text { SD) }\end{array}$ & Group 1 n=14 & $\begin{array}{c}\text { Group } 2 \\
n=6\end{array}$ & $\begin{array}{c}\text { Group } 3 \\
n=3\end{array}$ & $\begin{array}{c}\text { Total patients } \\
\qquad n=23\end{array}$ \\
\hline Age & $49 \pm 14.9$ & $57.2 \pm 9.7$ & $49 \pm 13.9$ & $51.3 \pm 13.5$ \\
\hline $\begin{array}{l}\text { Calcium mg/ } \\
\text { dl m }\end{array}$ & $11.2 \pm 1.3$ & $10.2 \pm 0.3$ & $10.9 \pm 0.9$ & $10.9 \pm 1.2$ \\
\hline $\begin{array}{c}\text { Calcium range } \\
\begin{array}{c}(8.4-10.2) \\
\mathrm{mg} / \mathrm{dl}\end{array}\end{array}$ & $9.9-12.2$ & $9.8-11.3$ & $10.1-11.8$ & $9.8-12.2$ \\
\hline $\begin{array}{c}\text { Phosphorus } \\
\mathrm{mg} / \mathrm{dl}\end{array}$ & $2.9 \pm 0.6$ & $3.26 \pm 0.9$ & $2.6 \pm 1$ & $3 \pm 0.7$ \\
\hline $\begin{array}{c}\text { Alk. } \\
\text { Posphatase } \\
\text { U/L }\end{array}$ & $131.8 \pm 115.3$ & $116.8 \pm 58$ & $210 \pm 205.7$ & $141.2 \pm 117.9$ \\
\hline Albumin g/dl & $4.3 \pm 0.3$ & $4.5 \pm 0.2$ & $4.2 \pm 0.9$ & $4.3 \pm 0.4$ \\
\hline $\begin{array}{c}\text { PTH-serum } \\
\mathrm{g} / \mathrm{ml}\end{array}$ & $262.9 \pm 304$ & $180.3 \pm 163.5$ & $630.7 \pm 862.9$ & $289 \pm 384.7$ \\
\hline $\begin{array}{l}\text { PTH-serum } \\
\text { range (normal } \\
12-72 \text { ) pg/ml }\end{array}$ & $53.6-1172$ & $53.8-493$ & $125-1627$ & $53.6-1627$ \\
\hline $\begin{array}{c}\text { PTH-washout } \\
\mathrm{pg} / \mathrm{ml}\end{array}$ & $2372.8 \pm 2021.6$ & $14.8 \pm 7.8$ & $15.9 \pm 9.8$ & $1515.5 \pm 1877.6$ \\
\hline $\begin{array}{l}\text { PTH-washout } \\
\text { range }\end{array}$ & $72.9-5000$ & $3-22.4$ & $6.1-25.8$ & $3-5000$ \\
\hline
\end{tabular}

Surgery was performed in 17 patients (group1 and 3), group 2 patients didn't undergo surgery as one patient went to settle in another country. Two patients were diagnosed to have concomitant colon cancer during investigations and three patients refused any surgical intervention and were given medical treatment instead. Calcium profile and PTH levels post operatively are shown in table 2 
Table 2: shows mean post-operative value of calcium and PTH-serum in groups 1 and 3 (the groups of patients who underwent surgery)

\begin{tabular}{|c|c|c|}
\hline Parameter & Group 1 & Group 3 \\
\hline Calcium mg/dl & $9 \pm 0.9$ & $9 \pm 0.1$ \\
\hline PTH-serum pg/ml & $81.4 \pm 124$ & $55.4 \pm 43.7$ \\
\hline
\end{tabular}

\section{Cyto-Histopathology}

In 4 patients out of the 23; FNA Bx was reported as a parathyroid lesion (17.4\%). In six cases the histopathology report was inconclusive and was reported; a parathyroid lesion versus a follicular thyroid lesion, four of them had positive PTH washout and those were proved to be parathyroid adenomas after surgery. Five FNA samples were reported as thyroid lesions and PTH washout was negative. Nine samples were inadequate for cytology reporting but five of them had positive results in PTH washout and those were proved to be parathyroid adenomas after surgical excision (see table 3). Cytology result was reported as Parathyroid lesion in 4 cases, Parathyroid vs. Thyroid in 5 cases, thyroid tissue in 5 cases and 9 cases reported as inadequate. 6 cases didn't undergo surgery.

The sensitivity of Cytology of parathyroid gland FNA is $28.6 \%$ and specificity of $100 \%$, it showed a $47.4 \%$ negative predictive value and $100 \%$ positive predictive value(see table 7 ).

Table 3: shows the number of cases with positive (parathyroid tissue) and negative (non-parathyroid tissue) results in cytology and histopathology among cases with positive and negative PTH-washout.

\begin{tabular}{|c|c|c|c|c|}
\hline & \multicolumn{2}{|c|}{ FNA-Bx (n=23) } & \multicolumn{2}{c|}{ Histopathology (n=17)* } \\
\hline $\begin{array}{c}\text { PTH- } \\
\text { washout }\end{array}$ & $\begin{array}{c}\text { Parathyroid } \\
\text { tissue }\end{array}$ & $\begin{array}{c}\text { Non } \\
\text { parathyroid } \\
\text { tissue }\end{array}$ & $\begin{array}{c}\text { Parathyroid } \\
\text { adenoma }\end{array}$ & $\begin{array}{c}\text { No } \\
\text { Parathyroid } \\
\text { adenoma }\end{array}$ \\
\hline $\begin{array}{c}\text { positive } \\
\text { (n=14) }\end{array}$ & 4 cases & 10 cases & 14 cases & 0 cases \\
\hline $\begin{array}{c}\text { negative } \\
\text { (n=9) }\end{array}$ & 0 cases & 9 cases & 3 cases & 6 cases* $^{*}$ \\
\hline *6 cases didn't undergo surgery & & \\
\hline
\end{tabular}

\section{PTH-washout}

Patients were divided into two groups; positive PTH washout and negative PTH washout .PTH level in the washout in those with positive results are many folds higher than those with negative results. ranging from 72.6 to $5000 \mathrm{pg} / \mathrm{ml}$ with a mean of $2372.8 \pm 2021.6 \mathrm{pg} / \mathrm{ml}$ while negative PTH washout ranged from 3 to $22.4 \mathrm{pg} / \mathrm{ml}$ with a mean of $15.2 \pm 7.9 \mathrm{pg} / \mathrm{ml}$. (see table 4 )

\section{Ultrasound}

In total, 15 patients out of 23 had an US reporting a parathyroid nodule, 4 patients had solitary thyroid nodules and one of these 4 had positive PTH washout but cytology was reported as inadequate, 2 had multinodular goiter with no evidence of a parathyroid adenoma. 2 patients had a nodule and the radiologist couldn't determine whether it's thyroid or parathyroid in origin. PTH washout was positive in 14 patients(see table 5) ; giving the
US alone a $76 \%$ sensitivity and $67 \%$ specificity with $87 \%$ positive predictive value and $50 \%$ negative predictive value (see table 7 ).

Table 4: comparison of results between the two groups showing ultrasound and surgical outcome for both groups

\begin{tabular}{|c|c|c|c|}
\hline mean $\pm S D$ & $\begin{array}{l}\text { PTH-washout } \\
\text { positive } n=14\end{array}$ & $\begin{array}{c}\text { PTH-washout } \\
\text { negative } n=9\end{array}$ & P-value \\
\hline Age, mean & $49.2 \pm 14.9$ & $54.4 \pm 11.1$ & 0.35 \\
\hline PTH-FNA range $(\mathrm{pg} / \mathrm{ml})$ & $72.9-5000$ & $3-25.8$ & \\
\hline PTH-FNA (pg/ml) & $2372.8 \pm 2021.6$ & $15.7 \pm 7.9$ & 0.0007 \\
\hline Serum-PTH range & $53.6 \pm 1172$ & $53.8-1627$ & \\
\hline Serum-PTH & $262.9 \pm 304$ & $330.4 \pm 503.5$ & 0.7 \\
\hline Serum Ca range & $9.9-12.2$ & $9.6-11.8$ & \\
\hline Serum-Ca & $11.2 \pm 1.3$ & $10.5 \pm 0.7$ & 0.1 \\
\hline $\begin{array}{c}\text { Number of patients with } \\
\text { positive scan }\end{array}$ & 11 & 3 & 0.04 \\
\hline $\begin{array}{c}\text { Number of patients } \\
\text { with US reporting } \\
\text { parathyroid adenoma }\end{array}$ & 12 & 3 & 0.01 \\
\hline $\begin{array}{c}\text { Number of patients with } \\
\text { surgical tx }\end{array}$ & 14 & 3 & 0.00008 \\
\hline $\begin{array}{c}\text { Number of patients with } \\
\text { proved adenoma by } \\
\text { Histopathology }\end{array}$ & 14 & 3 & 0.0008 \\
\hline
\end{tabular}

Table 5 : shows ultrasound results among cases with positive and negative PTH-washout result.

\begin{tabular}{|c|c|c|}
\hline $\mathrm{N}(\%)$ & $\begin{array}{c}\text { Ultrasound detecting } \\
\text { a parathyroid } \\
\text { adenoma n=15 }\end{array}$ & $\begin{array}{c}\text { Ultrasound } \\
\text { failed to detect } \\
\text { a parathyroid } \\
\text { adenoma n=8 }\end{array}$ \\
\hline $\begin{array}{c}\text { PTH-washout } \\
\text { positive }\end{array}$ & $12(80 \%)$ & $2(25 \%)$ \\
\hline $\begin{array}{c}\text { PTH-washout } \\
\text { negative }\end{array}$ & $3(20 \%)$ & $6(75 \%)$ \\
\hline
\end{tabular}

Of those who were reported to have a parathyroid adenoma by US; four of them had negative result on sestamibi scan, three of these cases had positive results in PTH washout which helped in confirming the adenoma and it was surgically removed successfully.

\section{SESTAMIBI Scan}

Among the cases which had negative results on sestamibi scanning there were 3 cases in which the radiologist detected a possible parathyroid adenoma and FNA was done with positive PTH-washout result, surgery and histopathology confirmed parathyroid adenoma. In the group with negative PTH- washout 
6 out of 9 had negative results on sestamibi scan (see table 6) Sestamibi scanning in this study had $76.5 \%$ sensitivity and $83.3 \%$ specificity with $92.9 \%$ positive predictive value and $55.6 \%$ negative predictive value (see table 7).

Table 6: shows sestamibi scan result among patients with positive and negative PTH-washout result.

\begin{tabular}{|c|c|c|}
\hline $\mathrm{N}(\%)$ & $\begin{array}{c}\text { SEATAMIBI positive } \\
\mathbf{n = 1 4}\end{array}$ & $\begin{array}{c}\text { SEATAMIBI } \\
\text { negative } \mathbf{n = 9}\end{array}$ \\
\hline $\begin{array}{c}\text { PTH-washout } \\
\text { positive }\end{array}$ & $11(78.5 \%)$ & $3(33 \%)$ \\
\hline $\begin{array}{c}\text { PTH-washout } \\
\text { negative }\end{array}$ & $3(21.5 \%)$ & $6(67 \%)$ \\
\hline
\end{tabular}

Table 7: shows the sensitivity, specificity, positive and negative predictive value of PTH-washout, ultrasound and sestamibi scan.

\begin{tabular}{|c|c|c|c|}
\hline & Ultrasound & $\begin{array}{c}\text { Sestamibi } \\
\text { scan }\end{array}$ & $\begin{array}{c}\text { PTH- } \\
\text { washout }\end{array}$ \\
\hline Sensitivity & $76 \%$ & $76.50 \%$ & $82 \%$ \\
\hline Specificity & $67 \%$ & $83.30 \%$ & $100 \%$ \\
\hline Positive predictive value & $87 \%$ & $92.90 \%$ & $100 \%$ \\
\hline Negative predictive value & $50 \%$ & $55.60 \%$ & $67 \%$ \\
\hline
\end{tabular}

\section{Surgery}

All of the 14 patients with positive PTH washout had successful surgical resection of the parathyroid adenoma (100\% specificity) as proved by the histopathology. All had normal calcium levels and normal PTH level post surgery. With no documented post operation complications. Among the nine patients with negative PTH washout only three underwent surgery with normal calcium and PTH levels post surgery. There were no reported intra or postoperative complications with average hospital stay of 3-4 days.

\section{Sensitivity, Specificity}

The overall sensitivity, specificity as well as PPV and NPV are summarized in table 7 showing that PTH washout by FNA give a superior confirmation and localization of parathyroid lesions preoperatively

\section{Discussion}

Successfulsurgical treatment of primary hyperparathyroidism in surgical candidates requires accurate localization of the parathyroid adenoma to help planning the surgery with less intraoperative time, less complications and shorter hospital stay.

Both Neck ultrasound and sestamibi scanning are used to localize parathyroid adenomas; with variable confidence; so that they can be removed surgically in case surgical management was required.

The most common cause of false positive results in ultrasound is the presence of concomitant thyroid nodules and radiologists expertise (14). In some cases the ultrasonographer can't distinguish a parathyroid lesion from a thyroid one; in our study the radiologist was able to report a parathyroid lesion using ultrasound in $65 \%(15)$ out of all 23 cases, but 2 of these 15 cases were falsely reported to have a parathyroid lesion and had negative results in histology and in PTH washout; confirming a non parathyroid lesion, giving a false positive result.

Sestamibi scan is an important method in localizing a parathyroid adenoma but it has some limitations. In our study 3 of the true positive cases; sestamibi scan failed to localize the lesion that US was able to identify as possible parathyroid lesion and PTH- washout was positive confirming a parathyroid lesion.

Three cases had falsely negative PTH washout. The possible explanation for having a negative PTH washout in these three cases is First one had a small right nodule on US $0.6^{*} 0.6 \mathrm{~cm}$ in size which was difficult to tell whether it's thyroid or parathyroid in origin with inadequate sampling in FNA, surgical exploration done 3 parathyroid and a half gland removed, on histopathology 2 and a half were unremarkable parathyroid glands and left inferior parathyroid adenoma. The second patient had a sizable nodule on US $3.5 * 1.5 \mathrm{~cm}$ consistent with a parathyroid adenoma which is concordant with sestamibi scan but sampling was inadequate. Surgery done with resection of right inferior parathyroid adenoma. In the third patient the adenoma was shown in SESTAMIBI scanning but US failed to localize it and it was spotted during surgery and its location was concordant with sestamibi scanning and it was reported as a parathyroid adenoma in histopathology. All three cases had normal calcium and PTH post surgery.

Regarding cytology it's difficult to distinguish a parathyroid cell from thyroid cell, the sensitivity yield also was low as it was shown by many investigators $(8,15,16)$. Our data shows the low sensitivity of cytology $28.6 \%$ making it a less reliable method in detecting a parathyroid adenoma (table 8). Four cases only were reported as parathyroid lesion by cytology; $17.4 \%$ of all cases. While 9 cases (39.1\%) were inadequate for definitive diagnosis. So PTH washout was superior to cytology in detecting a parathyroid lesion.

Table 8: shows the sensitivity of cytology in our study in comparison to other studies.

\begin{tabular}{|c|c|}
\hline Study & Sensitivity \\
\hline Guisti et al,2009 (2) & $16 \%$ \\
\hline Bancos et al,2012 (15) & $31 \%$ \\
\hline Abdelghani et al,2013 (5) & $29 \%$ \\
\hline Ketha et al,2014 (11) & $55 \%$ \\
\hline Current study & $28.6 \%$ \\
\hline
\end{tabular}

PTH washout showed a high sensitivity and specificity even when sampling was inadequate for cytology PTH was measured in the washout and when the result is positive this confirms that the sampled lesion is a parathyroid one.

Different studies used different cut off points of PTH washout; some considered a level $\geq 100 \mathrm{pg} / \mathrm{ml}$ a positive result $(9,10,11)$; others considered a PTH washout higher than concomitant PTH serum a positive result $(5,6,7,8)$. In our study we found that a cut 
off value was having PTH washout level higher than PTH serum revealed high sensitivity and $100 \%$ specificity.

Our study confirms the usefulness of PTH washout in confirming the parathyroid adenoma and it was superior to US and sestamibi scan alone as sensitivity of PTH washout was $82 \%$ and $100 \%$ specificity, with $100 \%$ positive predictive value and $67 \%$ negative predictive value (p value 0.0008 ) which is statistically significant compared to the other methods used in this study ; these results were close to results of other studies with a sensitivity range $82-100 \%$ and specificity range $91-100 \%$. $(2,5,6,11,15)$ as shown in table 9 .

Table 9: shows the sensitivity and specificity of PTH washout of our study in compared to other studies.

\begin{tabular}{|c|c|c|}
\hline Study & Sensitivity & Specificity \\
\hline Guisti et al,2009 (2) & $83 \%$ & - \\
\hline Bancos et al,2012 (15) & $84 \%$ & $100 \%$ \\
\hline Abdelghani et al,2013 (5) & $91.6 \%$ & $100 \%$ \\
\hline Ketha et al,2014 (11) & $82 \%$ & $100 \%$ \\
\hline Adamidou et al,2015 (6) & $85.7 \%$ & $100 \%$ \\
\hline Current study & $82 \%$ & $100 \%$ \\
\hline
\end{tabular}

There are no available studies about the risk and complications of parathyroid FNA but some complications have been described in some studies as fibrosis, abscess, hematoma and prolongation of surgery duration $(7,12)$. No such complications have been reported in our study during the FNA procedure, during surgery or upon histopathological reporting post operatively . None of the cases underwent surgery had a scar, fibrosis or abscess in the resected adenomas as was shown in a few cases in other reports $(7,12)$. The operator's experience in decreasing the number of passes, avoiding complications and reaching a diagnosis is crucial.

There are a few reported cases of cutaneous spread of parathyroid carcinoma after FNA (17), spread of malignant cells along the needle tract after FNA is very rare but it's a possible complication (18). Parathyroid carcinoma is very rare compared to parathyroid adenoma and clinical suspicion is pertinent to plan appropriate management, although the seeding of malignant cells are rarely reported; we recommend avoiding FNA when carcinoma is suspected as having a large palpable suspicious adenoma, very high PTH and bone involvement at diagnosis.

This study has some limitations of:

1. Ultrasound localization of parathyroid adenoma is operator dependent, radiological experience is crucial in this regard.

2. The sample size is small

3. Not all patients (true negative group mainly) underwent surgery that adds to the limitations of the study.

\section{Conclusion}

Our study showed that Parathyroid gland FNA with measurement of PTH washout has proved superiority in confirming parathyroid adenoma when PTH washout level is higher than serum with $82 \%$ sensitivity and $100 \%$ specificity and it can be used in cases where the Sestamibi scan and/ or US fail to localize the adenoma.

The detection of parathyroid cells by cytology adds to sensitivity but in most of the cases the cytology reports were non-conforming and rather confusing but even in these cases PTH washout measurement was sufficient in confirming the parathyroid adenoma.

Parathyroid FNA and PTH-washout is well tolerated and safe procedure making it an attractive method in the preoperative assessment to confirm the site of the adenoma in mainly in cases of doubtful US result and negative sestamibi scanning

\section{References}

1. Merlino JI , Ko K, Minotti A, McHenry CR. The false negative technetium$99 \mathrm{~m}$-sestamibi scan in patients with primary hyperparathyroidism: correlation with clinical factors and operative findings. The American Surgeon. 2003;69(3):225-229.

2. Massimo Giusti, Mara Dolcino, Lara Vera, Carla Ghiara, Francesca Massaro, Laura Fazzuoli. Institutional experience of PTH evaluation on fine-needle washing after aspiration biopsy to locate hyperfunctioning parathyroid tissue. J Zheijang Uni Sci .B 2009;10(5):323-330. Doi: 10.1631/jzus.B0820372

3. Doppman JL, Krudy AG, Marx SJ, Saxe A, Schneider P, Norton JA, et al. Aspiration of enlarged parathyroid glands for parathyroid hormone assay. Radiology 1983;148(1):31-35. Doi: 10.1148/ radiology.148.1.6856859

4. Archana M. Agarwal, Joel S. Bentz, Ryan Hungerford, and Dev Abraham. Parathyroid Fine-Needle Aspiration Cytology in the Evaluation of Parathyroid Adenoma: Cytologic Findings From 53 Patients, Diag Cytopathol. 2009;37(6):407-410. Doi: 10.1002/dc.21020

5. Abdelghani R, Noureldine S, Abbas A, Moroz K, Kandil E. The diagnostic value of parathyroid hormone washout after fine needle aspiration of suspicious cervical lesions in patients with hyperparathyroidism. Laryngoscope 2013;123(5):1310-1313. Doi: 10.1002/lary.23863

6. Fotini Adamidou, Panagiotis Anagnostis, Vasileios Champidis, Simoni Katergari, Georgios Zacharioudakis \& Marina Kita. The diagnostic value of parathyroid hormone washout after fine-needle aspiration in patients with primary hyperparathyroidism, Endocrine Abstracts. 2015;37:291. Doi: 10.1530/endoabs.37.EP291

7. Pierpaolo Trimboli, Federica D’Aurizio, Renato Tozzoli, Luca Giovanella. Risks and Benefits of Parathyroid Fine-Needle Aspiration with Parathyroid Hormone Washout, Endocrine Practice. 2012;18(4):441449. Doi: 10.4158/EP11148.0R

8. Fatih kuzu, Dilek Arpaci, Guldeniz Karadenzi, Ali Ugur Emre, Tarik Elri. Focused parathyroidectomy without intra-operative parathormone monitoring: The value of PTH assay in preoperative ultrasound guided fine needle aspiration washout, Annals of Medicine and Surgery. 2016;6:64-67. Doi: 10.1016/j.amsu.2015.12.065

9. Winters R, Friedlander P, Noureldine S, Ekaidi I, Moroz K, Kandil E. Preoperative Parathyroid Needle Localization: A Minimally Invasive Novel Technique in Reoperative Settings. Minimally Invasive Surgery. 2011;2011;1-4. Doi: 10.1155/2011/487076 
10.Slawomir Mikosinski, Piotr Jarek, Jacek Makarewicz, Stanislaw Sporny \& Lech Pomorski. The diagnostic value of PTH concentration in the needle washout after fine-needle biopsy of suspicious cervical foci in patients with hyperparathyroidism, Endocrine Abstracts. 2010;22:389.

11. Ketha Hemamalini, Lasho Michael A, Algeciras-Schimnich Alicia. Analytical and clinical validation of parathyroid hormone (PTH) measurement in fine-needle aspiration biopsy (FNAB) washings, Clin Biochem 2016;49(1-2):16-21. Doi: 10.1016/j. clinbiochem.2015.09.006

12.James Norman, Douglas Politz, and Irwin Browarsky, Diagnostic Aspiration of Parathyroid Adenomas Causes Severe Fibrosis Complicating Surgery and Final Histologic Diagnosis. Thyroid.2007;17(12):1251-1255. Doi: 10.1089/thy.2007.0081

13. Mariani G, Gulec SA, Rubello D, Boni G, Puccini M, Pelizzo MR et al Preoperative localization and radio-guided parathyroid surgery. J Nucl Med. 2003;44(9):1443-158.
14. Solbiati L, Osti V, Cova L, Tonolini M. Ultrasound of thyroid, parathyroid glands and neck lymph nodes. Eur Radiol 2001;11(12):2411-2424. Doi: 10.1007/s00330-001-1163-7

15. Irina Bancos; Clive S. Grant; Sarah Nadeem; Marius N. Stan; Carl C. Reading; Thomas J. Sebo, Risks and benefits of parathyroid fineneedle aspiration with parathyroid hormone washout. Endocr Pract. 2012;18(4):441-449. Doi: 10.4158/EP11148

16. Güven Barış Cansu, Bengür Taşkiran , Hayrettin Dizen , Betül Peker Cengiz. Parathyroid hormone in washout fluid seems to be superior to cytology for localization of the lesion in MIBI-negative patients with primary hyperparathyroidism, Turk J Med Sci. 2017;47:1703-1707.

17. Gaurav Agarwal, Sadhna Dhingra, Saroj K. Mishra, Narendra Krishnani. Implantation of parathyroid carcinoma along fine needle aspiration track, Langenbeck's Archives of Surgery. 2006;391(6):623-626.

18. Alwaheeb S, Rambaldini G, Boerner S, Coiré C, Fiser J, Asa SL. Worrisome histologic alterations following fine-needle aspiration of the parathyroid. J Clin Pathol. 2006;59(10):1094-1096. Doi: 10.1136/ jcp.2005.029017 